\title{
El ROMANCE NACIONAL CONTRA-ÉPICO EN BRENDA Y MINES DE EDUARDO ACEVEDO DíAZ
}

The National Contra-Epic Romance in Brenda and Minés by Eduardo Acevedo Díaz

\section{GERMÁN ANTONIO PitTA}

UNIVERSIDAD DE LA REPÚBLICA, Montevideo (Uruguay)

gpittabonilla@gmail.com

Resumen: en la narrativa uruguaya decimonónica existe toda una variedad de textos olvidados por el canon que proponen un abordaje diferente de la cuestión nacional. En este trabajo, me voy a ocupar de cierto sector de la obra de Eduardo Acevedo Díaz, dada su importancia en el desarrollo de la novela histórica, pero lo haré a través de dos de sus novelas (Brenda y Minés). En ellas se escribe el cuerpo patriótico de la nación en una clave sentimental y erótica. La nación es representada como un cuerpo femenino ambiguo y erotizado desde una perspectiva voyeurista. Como se verá, el voyeurismo es la política de la pose que define la escritura fundacional.

Palabras clave: Eros, nación, cuerpo femenino, novela sentimental, voyeurismo

Abstract: in the nineteenth-century Uruguayan narrative there is a whole variety of texts forgotten by the canon that propose a different approach to the national question. In this work, 1 am going to occupy a certain sector of the work of Eduardo Acevedo Diaz, given its importance in the development of the historical novel, but 1 will do it through two novels (Brenda and Minés). These novels write the patriotic body of the nation in a sentimental and erotic key. The nation is represented as an ambiguous and eroticized female body by a voyeuristic perspective. As it will be seen, voyeurism is the politics of the pose that defines the foundational writing.

Keywords: Eros, Nation, Female Body, Sentimental Novel, Voyeurism 


\section{El romance nacional uruguayo: la intrusión de lo sentimental}

Antes de hablar de la relación existente entre la mujer y el romance nacional, conviene revisar algunas de las definiciones propuestas por los críticos latinoamericanos que se han ocupado del tema.

Benedict Anderson es uno de los primeros investigadores en proponer una relación entre la nación y la novela. Si la nación es definida como una comunidad imaginada, todo esto es posible gracias a dos grandes discursos imaginarios: el periódico y la novela (Anderson, 2007: 46).

El trabajo de Anderson fue muy influyente para pensar la nación como una forma narrativa, y eso se constata en trabajos académicos tan importantes como la compilación realizada por Homi Bhabha (2010), titulada Nación y narración. Según el autor, la nación puede ser definida como una construcción ambivalente dada la tensión producida entre lo pedagógico y lo performativo. Lo pedagógico se refiere a la "presencia histórica de un a priori" y propone un marco de estabilidad. Lo performativo, en cambio, remite a aquellos "retazos y remiendos de la vida cotidiana" que jaquean cualquier forma de certeza y estabilidad de un discurso monolítico, proyectando lo que Bhabha denomina como "temporalidad del entremedio". En esa temporalidad intervienen los elementos residuales y emergentes que asedian a la forma dominante, tal como lo plantea Raymond Williams (2000) en su ensayo Marxismo y literatura.

Los enfoques desarrollados por Anderson y Bhabha constituyen una base teórica importante para comprender el concepto de "romance nacional", aplicado a las novelas latinoamericanas publicadas en la segunda mitad del siglo XIX. Por esta razón, propongo una breve presentación de algunas definiciones en torno a este concepto planteadas por Doris Sommer, Fernando Unzueta, María Fernanda Lander, Beatriz González Stephan, Silva Bouregard, Lee Skinner y Nathalie Bouzaglio.

Si hay algo que tienen en común los trabajos de Sommer, Unzueta y Lander es el pensar el romance nacional desde lo pedagógico. Para Sommer (2004), los romances latinoamericanos narran historias amorosas que representan determinadas regiones, razas, partidos e intereses económicos. Todos estos factores socio-históricos, representados como una historia amorosa, formarían parte de una "dialéctica alegórica" que permite corregir las aventuras funestas de sus pares europeos. Esta corrección estaría dada por la aspiración de las novelas a constituir matrimonios legítimos entre la familia y el Estado.

Unzueta sitúa su concepto de "romance nacional" como parte de una "escena de lectura": el romance nacional constituiría "un diálogo entre la tradición historicista, los discursos metatextuales del período y los romances mismos" (Unzueta, 2005: 7). Esta concepción metatextual de las novelas tiene que ver con un control ejercido por el propio autor acerca de cómo debe ser leído el texto. Incluso, más adelante, Unzueta llega a plantear la idea de una negociación entre lo patriótico, lo sentimental y lo histórico como forma de asegurar una finalidad ejemplarizante: las novelas mezclan el placer y la educación como una estrategia sentimental que afecta a la subjetividad del lector para realizar determinados objetivos morales, políticos y culturales.

El trabajo de Paulette Silva Beauregard, "Una receta contra la nostalgia: Zarate de Eduardo Blanco" (2012), propone una articulación dialógica diferente a la de Unzueta, ya que analiza la relación intertextual entre esa novela y la tradición folletinesca europea (particularmente con las novelas del escocés Walter Scott). La propuesta de esta autora es la separar el perfil de Eduardo Blanco como escritor patriótico debido a la exaltación de su "Venezuela heroica". Los vínculos 
con la narrativa folletinesca francesa convertirían a Blanco, como señala la propia autora, en una "planta exótica".

María Fernanda Lander, en su trabajo Modelando corazones. Sentimentalismo y urbanidad en la novela hispanoamericana del siglo XIX (2004), plantea que la función ejemplarizante de la novela se efectuaría por la relación intertextual entre las obras y los manuales de urbanidad de la época, entre ellos el conocido Manual de urbanidad y buenas costumbres de Manuel Antonio Carreño. Según Lander, las novelas continuarían con una tarea de disciplinamiento de los cuerpos; un fenómeno enmarcado dentro del proceso de modernización. En una línea similar, Beatriz González Stephan, al precisar la importancia que estos manuales tenían en la formación del buen ciudadano, afirma lo siguiente: "La cuestión era ser un hombre o mujer de apariencia civilizada, que sus modales no dejaran traslucir ningún rasgo o gesto que recordara viejos usos rurales, probablemente tildados de inciviles o bárbaros por esta nueva sociedad cada vez más estirada como moderna" (González Stephan, 1995: 194). Los romances podrían funcionar como verdaderas "ficciones domésticas", tal como lo plantea Nancy Amstrong (1991) para el caso de las novelas inglesas dieciochescas.

Javier Guerrero y Nathalie Bouzaglo, compiladores de Excesos del cuerpo. Ficciones de contagio y enfermedad en América Latina (2009), se ocupan de las relaciones existentes entre las textualidades latinoamericanas y el tema de la enfermedad. Según ellos, este tema fue prácticamente ignorado por la crítica. La enfermedad aparece en periódicos y en muchas novelas decimonónicas que presentan heroínas histéricas. Podría interpretarse que la enfermedad (y la histeria, en particular) constituye la amenaza que debe combatir la modernizacion, en su afán de crear un cuerpo civil sano.

Por último, Lee Skinner (2006) se ocupa del tratamiento del discurso religioso en el periodismo para definir el papel de las mujeres en la sociedad. En el artículo de Skinner se observa cómo el periodismo masculino manipuló el discurso religioso, concretamente la identificación de la mujer con la figura mariana, para "modelar" su personalidad y convertirla en una especie de monja del hogar. En este sentido, la figuración mariana puede entenderse como parte de una estrategia para crear a la formadora de los futuros ciudadanos.

Como puede verse en todas estos enfoques, el romance nacional opera en tanto una ficción correctiva porque incide en la difusión de ciertas ideas morales que harán florecer al futuro ciudadano. La ejemplaridad es el gran tópico que intenta plasmar la literatura decimonónica como parte del proyecto del liberalismo: la idea misma de una literatura nacional no se aparta de ese tono didáctico (González Stephan, 1987).

En el caso uruguayo, la construcción de un imaginario nacional constituyó el gran desvelo de sus letrados. Carolina González Laurino, en La construcción de la identidad uruguaya, da cuenta de los distintos abordajes propuestos desde la literatura y la historia. Así, durante la primera etapa de la modernización, la autora destaca la presencia del paradigma primordialista que buscaba definir a la nacionalidad de acuerdo con el modelo de la orientalidad. Para ello, se recurrió a figuras representativas de la barbarie como el indio indómito y el gaucho, presentes en la labor historiográfica llevada adelante por Francisco Bauzá y Carlos María Ramírez. Eduardo Acevedo Díaz se adscribe a este modelo en aquellas novelas que forman parte de la tetralogía (Ismael, Nativa, Grito de Gloria y Lanza y Sable). Por su parte, Juan Manuel Blanes lo hace a través de la representación pictórica (González Laurino, 2001: 22 y ss.). En todos estos casos, la orientalidad se comporta como la plasmación de un modelo épico masculino que excluye a la mujer del panteón nacional. Si estudiamos la pintura de Blanes, "El Altar de la Patria", observamos a una mujer con una túnica que cubre prácticamente todo su 
cuerpo, a excepción del rostro, las manos y los pies. Todos estos rasgos indican cierto grado de desexualización semejante al de una sacerdotisa (Peluffo, 1996).

Este modelo femenino desexualizado es también promovido por cierto sector de la literatura uruguaya, tal como lo sostiene María Inés de Torres (1995) en ¿La nación tiene cara de mujer? Mujer y nación en el imaginario letrado del siglo XIX. En dicho trabajo, la autora explica cómo se construye un imaginario nacional articulando distintos elementos, tales como la "nación" o la "familia". Siguiendo el planteo de Doris Sommer, la autora uruguaya argumenta que el discurso nacional necesitó, para formarse, de un discurso amoroso en el que la mujer aparece representada como madre o ser sufriente.

Por lo general, en las obras analizadas por María lnés de Torres, el modelo femenino está asociado a cierta idea de estabilidad, ya que la retórica familiar parece darle forma. Sin embargo, en las novelas publicadas a partir de los años ochenta del siglo XIX, encontramos la elaboración de un sentimentalismo ambiguo, generado por la emergencia y expansión del naturalismo, que provocó la combinación del discurso fisiognómico con el científico (Chouciño Fernández, 1999, 28: 547-562). Así, en Los amores de Marta de Carlos María Ramírez; Cristina de Daniel Muñoz, Las hermanas Flammari y Valmar de Mateo Magariños Solsona, Brenda y Minés de Eduardo Acevedo Díaz; este sentimentalismo ambiguo promueve una serie de desvíos. Los novelistas uruguayos, muchos de ellos estadistas, sienten el impacto de los debates filosóficos protagonizados por dos grandes corrientes: el espiritualismo y el positivismo y sus equivalentes literarios, el romanticismo y el naturalismo. $\mathrm{Si}$ vamos al caso de las novelas uruguayas finiseculares, nos encontramos con un caso típico de "sentimentalismo ambiguo", ya que el discurso del Ángel del hogar converge con otro modelo científico que relaciona a la mujer con su dimensión biológica. Si las novelas forman parte de la comunidad imaginada de la nación, se debe a que convierten el espacio ficcional de la novela en una continuación del debate político y filosófico generado en la tribuna periodística. Podríamos agregar que la novela plantea, a su vez, la continuidad de otro tipo de fenómeno social, no menos político: el imaginario corporal que emerge de la crónica elegante.

Todo lo dicho previamente permite modificar la apreciación que se tiene de las novelas sentimentales. Este género nos sitúa en una posición inmejorable para observar las grandes transformaciones sociales del momento. Las novelas sentimentales uruguayas dan cuenta de "nuevas escenas de lectura" que nos ayudan a leer la nación desde esa "temporalidad in media res" (Bhabha, 2010). Las significaciones parciales, no estabilizadas, son aportadas por los distintos discursos que convergen en las novelas: el discurso político y filosófico, el discurso científico, el discurso de la moda, el discurso folletinesco. No se debe olvidar que dichos discursos están presentes en el ámbito periodístico. Esta articulación dialógica permite pensar tal tipo de obras como "hipertextos variables", ya que las novelas absorben y transforman estos mismos discursos (Schaeffer, 2006).

\section{La secularización uruguaya y la creación de una nueva moral}

Una abundante bibliografía se ha dedicado a tratar el proceso de modernización como la gran transformación productiva, económica y cultural que experimentó el continente desde fines del siglo XIX hasta comienzos del siglo XX (Méndez Vives, 1998; Zubillaga y Cayota, 1988; Rodríguez Villamil, 2008). El historiador José Pedro Barrán, quien desarrolló un importante trabajo historiográfico en torno a la historia económica, se volcó más tarde al estudio de las mentalidades. En su Historia de la sensibilidad del Uruguay, ubica el proceso de la modernización entre los años 1860 y 1890, período que permitió el desarrollo de una "nueva sensibilidad civilizada" que acompañó las transformaciones en el campo 
demográfico, económico y político. Esta etapa coincide con lo que el autor denomina como el "disciplinamiento", impulsado desde el Estado centralizado mediante diferentes técnicas. En el plano educativo, una de las estrategias utilizadas fue el desarrollo de la reforma vareliana.

Un fenómeno cultural importante de la modernización lo constituyó la secularización. Este proceso de secularización puso en práctica una serie de reformas como las que enumero a continuación: 1) la municipalización de los cementerios, a partir de la prohibición de llevar los cadáveres a las iglesias (1861); 2) la aprobación del decreto-ley de Educación Común, que restringía la enseñanza religiosa en las escuelas estatales (1877); 3) creación del Registro de Estado Civil (1879); 4) el establecimiento del matrimonio civil como obligatorio antes del matrimonio religioso (1885); 5) la aprobación de la "Ley de conventos", con la que se buscó eliminar los centros dedicados a la vida contemplativa (1885); 6) la aprobación de la "Ley de Educación Secundaria y Superior" que permitió ejercer un mayor control sobre los centros de enseñanza (1885); 7) eliminación de los crucifijos de los hospitales públicos (1906); 8) Ley del divorcio absoluto por mutuo consentimiento (1907); 9) supresión de toda referencia religiosa (de Dios y de los Evangelios) en los juramentos realizados por los parlamentarios en el momento de asumir el cargo legislativo (1907); 10) consagración del laicismo a todo el ámbito de la instrucción pública (1909); 11) supresión de los honores oficiales en los actos religiosos y laicización del Código Militar (1911); 12) aprobación de la Ley del divorcio por la sola voluntad de la mujer (1913); 13) Separación oficial de la lglesia y el Estado (1919).

Toda esta enumeración de la serie de reformas realizadas, aunque no es del todo exhaustiva, permite dar cuenta de la secularización como un proceso que abarcó un extenso período de la historia del Uruguay. La particularidad de la secularización uruguaya estribó en "el carácter especialmente radical del concepto de laicidad impuesto en el país" (Caetano y Geymonat, 1996: 18). Esta radicalización se notó por la absorción del modelo francés, que se tradujo en dos notas distintivas: a) la marginación institucional de lo religioso y su radicación en el ámbito privado; b) las posturas fuertemente críticas que asumieron las autoridades uruguayas frente a la lglesia Católica. Esta exclusión de lo religioso de la vida pública respondía a la necesidad que tenía el Estado por crear una suerte de "religión civil": la sacralidad de lo religioso se transfirió a lo político. La vida civil adquirió esta "sacralidad" a través de la invención de rituales públicos, liturgias y de toda una simbología cívica que modeló los valores individuales de los ciudadanos. Resumiendo, las dos notas distintivas de la secularización uruguaya estarían dadas por la privatización de lo religioso y la instauración de una "religión civil" (Caetano y Geymonat, 1996: 19).

La discusión de estos proyectos en el ámbito parlamentario promovió una serie de confrontaciones relacionadas con los límites y alcances de la privacidad y la intimidad de los individuos. La reivindicación de la intimidad como parte de una "nueva sensibilidad" comenzaba a ganar terreno en la agenda ciudadana. Al respecto puede consultarse el trabajo de José Pedro Barrán, Intimidad. Divorcio y nueva moral en el Uruguay del Novecientos (2008).

La lglesia Católica no permaneció impasible frente a los embates de este impulso secularizador. La respuesta se manifestó a través de la guetización del mundo católico, lo cual implicó un fuerte disciplinamiento de sus miembros y el desarrollo de un "feminismo cristiano" mediante el culto al Ángel del hogar.

Susan Kirkpatrick ubica el desarrollo de este modelo en España a partir de 1840. En la génesis del concepto, afirma que fue Pedro Sabater quien definió a la mujer como "ángel descendido del cielo", cuya principal característica sería la de dar amor. La psique femenina se definiría exclusivamente por esta cualidad, descartando cualquier otra de índole intelectual o sexual (Kirkpatrick, 1989: 63- 
65). El concepto de la mujer doméstica se difundió en el Río de la Plata, y en el caso concreto del Uruguay encontramos varias publicaciones periódicas ( $L a$ Tribuna Popular, El Ferro-carri) que construyen discursivamente a los referentes "hogar" y "maternidad". En todos ellos se insiste en la misión primordial a cumplir por parte de la mujer: si como sostiene Masiello (1997) la familia y el hogar configura la nación poscolonial, a la mujer le corresponde el papel de formar a esos futuros ciudadanos.

Este último se basó en la promoción y revitalización del culto mariano como medio estratégico de preparar a la mujer para desenvolverse en ese nuevo mundo de la privacidad. La prédica del Arzobispo de Montevideo, Mariano Soler, puso su énfasis en el papel decisivo que tenía la mujer como "reina en el hogar y señora en la sociedad". Según Soler, la mujer debía cumplir una misión muy precisa en el hogar doméstico: "si el hombre hace las leyes que rigen los destinos sociales, la mujer es la que forma las costumbres. El hombre manda; pero la mujer es la que dicta las lecciones y consejos, que representan el imperio moral" (Caetano y Geymonat, 1996: 34-35).

Pero esta mujer, confinada en el hogar, convivió con otra tendencia que se oponía a esta "marianización privada"; me refiero a la transformación de la mujer en un objeto estético. Esta nueva visión de lo femenino ingresa merced al nuevo imaginario de la moda asociado al gusto burgués por los objetos suntuarios. Así, Silvia Rodríguez Villamil nos explica lo que entiende como una línea de continuidad entre la presencia del lujo en el mobiliario, la arquitectura y la nueva imagen del cuerpo:

Sin pretender un análisis del fenómeno de las modas con todas sus connotaciones, interesa destacar algunos aspectos en que la preocupación por la apariencia exterior de hombres y mujeres se emparentaba con la importancia simbólica atribuida a las fachadas de viviendas o la decoración escenográfica de los interiores. La alusión al teatro parece pertinente dada la importancia fundamental que se asignaba entonces al ver y al ser visto. Tal como actores caracterizados para encarnar determinado rol, hombres y mujeres burgueses debían presentar ante los demás (e incluso ante ellos mismos) una imagen acorde con la posición social que ocupaban y con las concepciones dominantes sobre lo masculino o lo femenino. (Rodríguez Villamil, 1996: 101-102; las cursivas son mías)

La autora es capaz de percibir el componente teatral del cuerpo: una gestualidad escénica y no menos estatuaria que se le impone a la mujer convertida ahora en una criatura del deseo. En ese mismo artículo, Rodríguez Villamil se ocupa de señalar cómo las modas femeninas debían adaptarse a ciertos cánones de belleza: la cintura de avispa conseguida mediante el corsé formaba parte de esas búsquedas. A la hora de evaluar el uso de estas prendas, la historiadora observa una profunda contradicción entre los cánones de la moda y la moral puritana a la que debía ajustarse la mujer: la represión de la sexualidad femenina mediante la imposición del recato y la parsimonia contrastaba con el deseo de exhibir a la mujer en público. Acicaladas y sofisticadas en el vestir, estas mujeres constituían un gran espectáculo visual, donde su condición decorativa y ornamental se acentuaba notablemente. Su sensualidad tendía a destacarse al optar por vestidos muy ceñidos al cuerpo que provocaban una actitud voyeurista en los hombres: la mirada masculina asomaba en cualquier ocasión, particularmente en los teatros, ya que las mujeres solían ubicarse en ciertos lugares accesibles a las miradas ardientes de los varones. Todo este espectáculo visual propone un marco ambiguo de represión e incitación que deriva en una exacerbación del erotismo (Rodríguez Villamil, 1996: 106-108). 
El emergente erótico asociado al corsé provocó un desvío de cierto modelo que tendía a privilegiar la condición reproductiva de la mujer. El ideal materno y angelical buscó representarse mediante la exaltación de las caderas redondas y los senos abundantes, pero estos signos anatómicos de la fertilidad empezaron a ser percibidos desde una mirada deseante. En el caso de las novelas uruguayas publicadas entre 1880 y 1907, este horizonte de lo pedagógico es sacudido por lo performativo. La mujer asume involuntariamente una política de la pose impuesta por el deseo masculino y, por lo tanto, muy diferente al uso cultural que le adjudica Molloy. Para la autora, la política de la pose constituía una puesta en escena del amaneramiento, la visibilidad de lo no masculino; sin embargo, más adelante, Molloy afirmará que la pose incluye otro itinerario: la pose remite a lo no mentado (Molloy, 2012: 47-49). Aquello no mentado en las novelas uruguayas del período corresponde con un "emergente" erótico que se presenta como un elemento en preformación (Williams, 2000).

\section{Escribir la patria en el cuerpo}

La obra de Eduardo Acevedo Díaz (1851-1921) fue valorada de acuerdo con su influjo en el desarrollo de la novela histórica, y esto llevó a la producción de una crítica literaria que se concentró en el estudio de su tetralogía compuesta por las siguientes novelas: Ismael (1888), Nativa (1890), Grito de Gloria (1893) y Lanza y sable (1914). Fuera de estas obras que siguen de cerca los episodios históricos que permitieron la obtención de la independencia, también han merecido la consideración crítica Soledad y El combate de la tapera. Sus otras dos novelas, Brenda (1883) y Minés (1907), en cambio, fueron prácticamente silenciadas y cuando son mencionadas, se las concibe como obras menores del autor.

Esta clasificación en la que se distinguen dos niveles jerárquicos se funda en una aplicación bastante equívoca del concepto "novela histórica". El enfoque de Lukacs prioriza la obra de acuerdo con la exteriorización de ciertos valores colectivos que definen el proyecto vital humano. El autor húngaro consideraba que lo importante de la novela histórica estribaba en saber por qué los hombres habían actuado de determinada forma; lo que importaba más, no era tanto el protagonismo individual de los héroes, sino las razones sociales que habían llevado al héroe a actuar así (Lukács, 2003). Este criterio de objetividad, que en no pocos casos se vincula con una mirada "realista", no hizo otra cosa que oscurecer la visión del fenómeno. El problema surge cuando se pretende separar a la novela histórica del romanticismo. Noe jitrik, por su parte, ha demostrado de qué forma el movimiento romántico sentó las bases del imaginario que hizo fructificar a este género considerado como un "oxímoron autorizado" (Jitrik, 1995: 12-13). Si en algo coinciden la novela histórica y el romanticismo, es en esa necesidad que sienten por volcarse al pasado para encontrar respuestas a una crisis con las que intentan dar cuenta de una identidad a nivel social.

Eduardo Acevedo Díaz hizo fructificar ese "oxímoron autorizado" en sus dos novela "menores", al plantear en sus prólogos una defensa del género sentimental tan identificado con el romanticismo. La pervivencia del romanticismo no estaba desligada de su concepción moral de la literatura que lo llevará a pensarse como "obrero de las multitudes" (Correa, 2012; Armand Ugón, 2012).

Las novelas de Eduardo Acevedo Díaz no suelen ser pensadas como obras eróticas. Incluso, si se examina su correspondencia familiar, tampoco se hace ninguna mención a este tema (Galmés, 1980). No obstante, pese a ese idealismo que siempre lo caracterizó, en dos cuentos, aparecidos en la prensa periódica con los títulos de "Columpio" e "Idilios precoces", el novelista quiebra ese límite y llega a plantear el universo infantil y la exploración del erotismo (Rocca, 1996: 158). 
Como se verá en el análisis de las novelas, esa función didáctica de la literatura lo llevará a plantear una erotización del cuerpo femenino, alejándose de las expresiones instintivas que caracterizan a la cultura bárbara. Al hablar de erotismo, estamos pensando fundamentalmente en el significado que esa palabra adquiere a mediados del siglo XIX. La noción "arte erótico" surge en la estética para dar cuenta de los fenómenos de materia sexual diferenciables de la pornografía. Tanto Pater como Cousin pensaban que la misión del arte consistía en perseguir intensamente el ideal de la belleza; el arte era concebido como un círculo especial, un mundo aislado y autónomo puesto al servicio del placer.

Las doctrinas de Victor Cousin y Walter Pater se difundieron en el Uruguay bajo el magisterio de Plácido Ellauri, uno de los representantes de la corriente espiritualista. Aunque los letrados uruguayos nunca llegaron a emplear la palabra erotismo o arte erótico, parece que de algún modo llegaron a plasmar esta noción al reflexionar acerca de la belleza ideal. Además, toda esta imaginería estética venía siendo impulsada por toda la cultura finisecular que, como bien observa Litvak (1979) presenta toda una mística sensual a través de joyas, objetos y vestidos (Litvak, 1979: 119). El erotismo es pensado como una "búsqueda psicológica independiente", separada de toda finalidad reproductiva y de toda norma social (Bataille, 2007: 15-33). Esta búsqueda se observa en las novelas por la atención que pone el narrador en la descripción estatuaria y escultórica del cuerpo femenino. El detalle del corsé se convierte en una prenda que concentra todo el deseo.

En la primera de estas dos novelas, Brenda, el lugar que debe ocupar ese cuerpo-nación es de algún modo problematizado en la discusión que sostienen Raúl Henares y Zelmar Bafil. Dos formas de subjetivación se contraponen. Para Bafil, estudiante de medicina, "Venus está detrás de toda esa muselina", la mujer angelical oculta y atempera al instinto. Venus como metáfora corporal está presente en esa "scientia sexualis" que, como había observado Foucault, no puede separarse de un ars erótica. En el discurso un tanto ampuloso de este personaje, la visión positivista del cuerpo femenino busca hacerse un lugar. La mujer como devoradora sexual, que se corresponde con la concepción naturalista, compite con otra imagen más espiritualizada. Esa estela del ensueño es la que perseguirá Raúl Henares. El erotismo corporal del discurso médico se opone al erotismo de los corazones. Estos dispositivos corporales estarán representados en la lucha silenciosa que entablarán dos personajes: Brenda Delfor y Areba Linares.

Las diferencias que mantienen estos personajes son visibles en su primera presentación. Areba linares sobresale en el paseo público por su descripción estatuaria del cuerpo elegante. Las trazas tenues de lo angelical son opacadas por su sensualidad y elegancia. Durante el siglo XIX, las novelas convierten en un verdadero tópico ciertas descripciones corporales; por ejemplo, es muy recurrente la atención concedida al seno alto y turgente. El cuerpo femenino es objeto de una política de la pose. En el caso de Areba, la pose que se le impone intenta marcar la escenificación de una sensualidad peligrosa.

Muy diferente es la primera presentación de Brenda. En el capítulo que lleva por título "La losa negra", Raúl encuentra a Brenda visitando la tumba de su padre, muerto en una guerra civil. Este encuentro es importante porque el cementerio se carga de cierta significación; la tumba delinea la figura del cuerpo masculino heroico como una ausencia. Pedro Delfor (nombre que conoceremos más adelante cuando nos enteremos de las circunstancias que rodearon a su muerte y que involucran al propio Raúl) representa la ferocidad y la barbarie de las guerras civiles que la sociedad debe dejar atrás para forjar un nuevo ideal de nación. Esta escena también es importante porque Brenda es descripta como un cuerpo angelical; sus cualidades etéreas refuerzan la nota de lo evanescente. 
Brenda aparece como la hija devota que acude al cementerio a rendirle un homenaje a su padre.

Cuando se hace referencia a su cuerpo, el narrador nos lleva a reparar en su figura esbelta. Sin embargo, en este caso, la esbeltez de su figura no asume esa connotación de peligrosidad que veíamos en Areba debido a que en la primera la blancura constituye una marca hegemónica de su personalidad.

Con posterioridad a este encuentro, Raúl no cesará de pensar en ella como ideal de la nueva nación. El cuerpo virgen de Brenda aparece como la condición necesaria para construir otro tipo de sociabilidad al margen de lo épico bárbaro. $Y$ para diferenciar los dos tipos de subjetivaciones en torno a lo femenino, apela a metáforas provenientes del mundo animal. Este constructor de soberanía ya no elige al león como representación del poder, sino a la "tímida gacela" (Brenda) para oponerla a la "leona núbil" (Areba). El león representa a aquella ferocidad instintiva que hay que mitigar mediante figuraciones animales más pacíficas. $Y$ sólo la mujer como "monja del hogar" (Brenda) puede hacerlo.

El otro campo metafórico subjetivante es tomado del campo floral. Aquí Brenda es vista como una "rosa pálida" frente a la "rosa mosqueta" que representa a Areba. En este caso, la sencillez y pureza nativa de Brenda se contrapone a la falsedad y el artificio.

La sencillez nativa de Brenda pone un freno al sensualismo. Si bien el sensualismo, que el letrado del siglo XIX asocia con la lujuria, debe ser controlado, el novelista decimonónico no cesa de requerirlo. En varias ocasiones encontramos descripciones de Brenda que bordean un sensualismo atenuado: "Plegábase a la cintura el elegante corpiño haciendo sobresalir las moldeadas formas de su busto esbelto [...]. Se exhalaba de esta hermosa criatura como un aroma sutil y embriagante vergel que iba a la cabeza y tentaba el vértigo" (Acevedo Díaz, 1883a: 115). En este pasaje hay un juego de intermitencias. Precisamente, Roland Barthes nos recordaba en El placer del texto que lo erótico es una "intermitencia" o "puesta en escena de una aparición-desaparición" (Barthes, 1980a: 19). La mujer es objeto de una política de la pose porque representa (en el sentido teatral del término) el deseo del otro.

La intermitencia se produce cuando las imágenes etéreas son interceptadas por otras más voluptuosas. El narrador, instalándose en la conciencia de Henares, observa el cuerpo deseado enmarcándolo en una erótica de lo floral: las referencias a zonas corporales como el seno y el corpiño quedan asociadas a elementos naturales.

Por otra parte, el motivo indumentario también adquiere su importancia para dar cuenta de este erotismo corporal. La vestimenta permite ocultar y sugerir, enseñando el cuerpo en forma atenuada. El deseo masculino es mostrado en una dirección dual que integra armónicamente la exterioridad física y la interioridad espiritualizada.

Todo esto nos permite comprender por qué su oponente, Areba Linares, está excluida del altar de la patria. En ella encontramos a un personaje cautivo de pasiones ardientes, la indocilidad del deseo la arrebata y la aleja de la serenidad angelical que, en cambio, posee Brenda. La confrontación entre los personajes es mostrada incluso en distintos escenarios sociales, como el baile en la casa de los Stewart. La escena en cuestión revela de qué forma funciona la sociabilidad elegante en las postrimerías del siglo XIX. Alfredo Castellanos observa que en este tipo de reuniones, característicos de la "Belle Ėpoque", "las mujeres jóvenes y sobre todo jovencitas rivalizaban en belleza y elegancia" (Castellanos, 1981: 7). La escena del baile propone otra danza de los cuerpos, enfrentados a través de verdaderas políticas (eróticas) de la pose. Mientras que Areba se deshace en las tensiones corporales indómitas, Brenda resplandece como una simbiosis armónica de la angelidad y la voluptuosidad: "sus encantos sin artificio, de conjunto 
afiligranado, perfiles correctos, tul negro, cabellera rubia, expresión dulce, sencilla, ojos de un azul profundo, el seno alto y turgente, las manos pequeñas, color rosa pálida" (Acevedo Díaz, 1883a: 265).

Brenda es una novela que parece plantear una transición de un tipo de novela a otro; esto es, de una novela épico patriótica (que exalta el cuerpo bárbaro e indisciplinado) a otra que tiende a desarrollar la cultura visual de la Belle Epóque. La dimensión erótica del cuerpo emerge en el desfile urbano de la fiesta social. Con la siguiente novela, Minés, dado que aparece catorce años después, acusa los cambios históricos y sociales que se vienen desarrollando en el seno de la generación del 900. Dado que esta generación se animó a promover en sus obras ciertos modelos estético sexuales, creo que Acevedo contaba con otro grado de libertad para cultivar el erotismo, ya no sólo desde la mirada, sino también desde la reivindicación del deseo. Por supuesto que esta reivindicación la hace refugiándose desde el pudor que caracterizó a toda su obra narrativa.

Con Minés, novela publicada en 1907, Acevedo ingresa en dos problemáticas históricas: las guerras civiles y el problema religioso. Este último tema tiene que ver con el conflicto entablado entre católicos y liberales en el seno de la primera etapa de la modernización uruguaya. Durante la década del ochenta del siglo pasado, los distintos gobiernos nacionales tomaron algunas medidas tendientes a eliminar la hegemonía religiosa en la vida civil. Este avance de la secularización fue resistido con tenacidad por parte de la lglesia católica, y esa resistencia se hizo manifiesta a través de la figura del arzobispo de Montevideo Mariano Soler. Según Caetano y Geymonat, la lglesia católica proyectó una perspectiva de género al representar a la mujer mediante el modelo mariano constituyendo un "apostolado femenino" (Caetano y Geymonat, 1997: 217-220). Con este modelo, la lglesia buscó alejar a la mujer de todas las tentaciones mundanas (la indumentaria, el lujo) promoviendo una territorialización corporal que acentuaba la importancia del corazón como enclave metonímico del sentimiento.

Este modelo mariano asoma en la primera descripción del personaje: "predispuesta al ensueño en la edad más propicia a los vuelos del sentimiento exaltado..." (Acevedo, 1883: 28). Parecería que el modelo angelical funcionara a la perfección en esta primera parte de la novela. Sin embargo, ese ideal difuso e incorpóreo es entrecortado por ciertas notas de voluptuosidad: "un cuerpo esbelto de formas griegas, el rostro de perfiles correctos [...] bajo la sencilla vestimenta azul sus curvas graciosas..." (Acevedo, 1883: 36). Estamos ante un acceso a la voluptuosidad corporal bajo los signos de una imagen infantil. Otra vez encontramos la pose en la perspectiva voyeur del narrador.

En este y otros pasajes, el erotismo vuelve a presentarse como una intermitencia: las curvas graciosas son sugeridas por el vestido azul, indicio de una angelidad e inocencia que controla, aunque sugiere, la peligrosidad del deseo. Toda la primera parte de la novela parece ajustarse a una modalidad característica del discurso amoroso: la idealización del ser amado (Zo, 2007: 89-90). Por su parte, Barthes ya había intuido esta forma cuando señalaba que el discurso amoroso "es una envoltura que se ciñe a la lmagen, un guante muy suave en torno al ser amado. Es un discurso devoto, bienpensante" (Barthes, 2010b: 36).

Tanto Ricardo como Minés desarrollan alternativamente un discurso amoroso "devoto, bienpensante". Minés lo hace a través del retrato; creyendo representar los rasgos de Jesús, no hace otra cosa que reproducir la figura de su amado Ricardo. El código del arte, un "mediador estético", activa el deseo, la percepción del cuerpo del otro. Ricardo, por su parte, apela al código de la escritura, a la carta como forma del discurso amoroso que "busca detallar la imagen del otro en puntos variados que la carta intentará tocar" (Barthes, 2010b: 60-63). Mediante la retórica de la carta, el discurso delinea el contorno sagrado 
del cuerpo del otro, pero poco a poco produce un desborde del significante hacia la exaltación de las delicias terrenales.

El discurso epistolar de Ricardo es el recurso elegido para desarrollar una crítica anticlerical. $Y$ aquí, Minés se erige como un cuerpo de la nación deseado al margen de ese "apostolado femenino" defendido en la novela por Martín Gardello (sacerdote amigo de Ricardo). De hecho, las propias dudas experimentadas por Minés (el debate interno entre el voto sagrado y las emociones profanas) van conformando los distintos senderos de la nación: la orientación católica o la tendencia a la secularización.

La guerra civil aparece en este horizonte como el otro gran escollo de la nacionalidad. Durante la segunda mitad del siglo XIX hubo muchas voces que se levantaron contra la guerra considerada por José Pedro Varela como "ese estado normal de la República" (Barran, 2011: 37). Este estado se correspondía, según el historiador uruguayo, con aquella sensibilidad bárbara promotora de una atmósfera lúdica y de la insolencia del cuerpo. La guerra favorecía la indisciplina sexual ligada exclusivamente a la satisfacción física e instintiva.

Los dos personajes ingresan en la guerra por caminos muy distintos; Ricardo lo hace como soldado movido por una de las divisas en pugna; Minés lo hará bajo su condición de monja y se dedicará a curar de los heridos. El modelo la "Monja del hogar" o del "bello ángel de amor" (según las palabras utilizadas por Carlos María Ramírez) sobresale en ella. Pero del mismo modo que la lectura de la carta logró despertar en ella impulsos desconocidos, al ver a Ricardo entre los heridos "una transformación repentina se fue operando en ella a medida que la emoción iba en aumento, y, bajo su dominio le echó los brazos al cuello" (Acevedo Díaz, 1907b: 260).

El erotismo se manifiesta a partir de aquí y lo hace apoyándose en imágenes religiosas. Toda una atmósfera transgresora, en el sentido planteado por Bataille, reaparece para dar rienda suelta al deseo. El carácter transgresor del deseo es confesado por ella misma cuando afirma que para él "reservaba mis grandes idolatrías sin más pensar en el claustro".

Otro aspecto del erotismo trabajado por Bataille y que está presente en esta escena, tiene que ver con la relación entre erotismo y muerte o sacrificio ritual. La proximidad de la muerte visible en el sacrificio lleva a afirmar a Bataille que se trata del único instante de vitalidad y plenitud: el autor lo denomina como la "plétora de los órganos". La escena a la que me refiero corresponde al delirio de Ricardo: "Ricardo llevó de repente las manos crispadas al vendaje, que destrozó en parte, pero ella lo cogió de las muñecas con increíble vigor, afirmándose con las rodillas en la cama, y por largos segundos se debatieron los dos en terribles sacudidas" (Acevedo Díaz, 1907b: 285).

En toda la descripción de la escena, los movimientos convulsos de los personajes se asemejan a aquellos que normalmente desarrollan en el acto sexual. La escena puede verse en su reverso como la manifestación interna del deseo que no llega a consumarse en la novela: el deseo comparece camuflado en una ayuda caritativa por parte de este ángel de amor. Toda la escena pertenece al signo ambivalente; en los últimos momentos vemos a Minés "sofocada y jadeante" (signos del erotismo que la recorre), pero también exhibe los signos de su angelidad al decir "Dios eterno, apiádate de mi" (Acevedo Díaz, 1907b: 287). Son las últimas palabras pronunciadas por el personaje antes de morir.

El sacrificio de Minés simboliza ese nuevo pacto que funda una nueva nación. $Y$ aquí el modelo angelical parece funcionar en varias direcciones; por un lado, el ángel como medio para moderar las pasiones desenfrenadas por la guerra; por otro lado, la defensa del erotismo como factor emergente buscaría crear otro cuerpo de la nación alejado del modelo etéreo católico. El camino de la secularización parece iniciarse al integrar lo angelical y la voluptuosidad. 


\section{Reflexiones finales}

En este trabajo, he querido mostrar de qué forma la novela histórica, entendida como un "romance nacional", puede dar cuenta de lo que he denominado como los usos del cuerpo en la escritura de la nación. Sin duda, el escritor escribe sus páginas conformando novelas, pero en este caso particular no resultaría extraño decir que esa misma página está representada por el cuerpo femenino. El concepto de política de la pose que he utilizado en este artículo tiene que ver con esto último: el novelista hace un uso del cuerpo femenino. $Y$ ese uso determina una posición velada, no del todo manifiesta, en esa construcción del deseo.

Por otra parte, esa política de la pose es fundamentalmente erótica porque en las novelas analizadas el eros constituye un excedente o un emergente. Si bien las novelas llamadas patrióticas expresan su deseo de escribir la nación en la superficie de cuerpos disciplinados y angelicales, en estas novelas uruguayas encontramos una ambigüedad en ese itinerario del deseo. La búsqueda del cuerpo angelical como altar de la nación no excluye esa persecución de lo erótico. Si el narrador asumía la postura de un voyeur era porque su mirada se dirigía a otra representación de lo femenino. Esta nueva representación no estaba desligada de esa tendencia a la secularización, proceso iniciado en las últimas décadas del siglo XIX y continuado en la primera mitad del siglo siguiente.

Dicho avance de la secularización uruguaya parece querer armonizar el puritanismo con las formas de una sensualidad no declarada. Por esta razón, la ambigüedad es el signo constitutivo de estas novelas.

\section{BiBLIOGRAFÍA}

ACEvedo DíAZ, Eduardo (1883), Brenda. Buenos Aires, Imprenta de La Nación. (1907), Minés. Buenos Aires, Imprenta de La Nación.

ARMSTRONG, Nancy (1991), Deseo y ficción doméstica: una historia política de la novela. Madrid, Ediciones Cátedra.

ANDERSON, Benedict (2007), Comunidades imaginadas. Reflexiones sobre el origen y difusión del nacionalismo. México, Fondo de Cultura Económica.

ARMAnd Ugón, Pablo (2013), "Eduardo Acevedo Díaz en el siglo XIX: obrero del ideal para las muchedumbres". Consultado en $<\mathrm{http}$ //www.fhuce.edu.uy/index.php/letras/seccion-de-archivo-y-documentaciondel-instituto-de-letras/publicaciones/ponencias/2191-ponencias-del-seminarioenfoques-sobre-literatura-y-cultura-en-america-latina-el-siglo-xix> (29/07/2017).

BARRÁN, José Pedro (1988), Iglesia católica y burguesía en el Uruguay de la modernización (1860-1900). Montevideo, FHCE. Departamento de Publicaciones. (1992), Medicina y sociedad en el Uruguay del Novecientos: la invención del cuerpo, V. 3. Montevideo, Ediciones de la Banda Oriental.

Barrán, José Pedro; Caetano, Gerardo et alter (1996), Historia de la vida privada en el Uruguay. El nacimiento de la intimidad (1870-1920), Tomo 3. Montevideo, Editorial Santillana. (2008), Intimidad. Divorcio y nueva moral en el Uruguay del Novecientos. Montevideo, Ediciones de la Banda Oriental. (2011), Historia de la sensibilidad. Montevideo, Ediciones de la Banda Oriental.

BARTHES, Roland (1980), El placer del texto. Bogotá, Siglo XXI. (2010), Fragmentos de un discurso amoroso. Buenos Aires, Siglo XXI.

BATAILlE, Georges (2007), El erotismo. Barcelona, Editorial Tusquets.

BHABHA, Homi (Comp.) (2010), Nación y narración. Buenos Aires, Siglo XXI. 
BRENNAN, Thimoty (2010), "La nostalgia nacional de la forma", en Bhabha, Homi (Comp.), Nación y narración. Buenos Aires, Siglo XXI, pp. 65-99.

CAETANO, Gerardo y Geymonat, Roger (1997), La secularización uruguaya (18591919). Catolicismo y privatización de lo religioso. Montevideo, Ediciones Santillana.

CASTELLANOS, Alfredo (1979), La Belle Époque montevideana. Vida social y paisaje urbano. Montevideo, Editorial Arca.

CHOUCIÑO FERNÁNDEZ, Ana (1999), "Apuntes para una revisión de la narrativa sentimental hispanoameriana: Carmen de Pedro Castera", Anales de Literatura Hispanoameriana, n. ${ }^{\circ} 28$, pp. 547-562.

CORREA, Felipe (2013), "Los artículos metaliterarios de Eduardo Acevedo Díaz". Consultado en <http://www.fhuce.edu.uy/index.php/letras/seccion-de-archivo-ydocumentacion-del-instituto-de-letras/publicaciones/ponencias/2191-ponenciasdel-seminario-enfoques-sobre-literatura-y-cultura-en-america-latina-el-siglo-xix > (29/07/2017).

FouCAult, Michel (2011). Historia de la sexualidad I. La voluntad del saber. Buenos Aires, Siglo XXI.

GAlmÉs, Héctor (1980), Correspondencia familiar e íntima de Eduardo Acevedo Díaz (1880-1898). Montevideo, Biblioteca Nacional.

GONZÁlEZ LAURINO, Carolina (2001), La construcción de la identidad uruguaya. Montevideo, Editorial Taurus.

GONZÁlEZ STEPHAN, Beatriz (1987), La historiografía literaria del liberalismo hispanoamericano del siglo XIX. La Habana, Editorial Casa de las Américas.

(1995), "Modernización y disciplinamiento. La formación del ciudadano: del espacio público y privado", González Stephan, Beatriz et alter (eds.), Esplendores y miserias del siglo XIX: cultura y sociedad en América Latina. Caracas, Monte Ávila.

(2000), "Narrativas duras en tiempos blandos: sensibilidades amenazadas de los hombres de letras", Revista de Crítica Literaria Latinoamericana, Año XXVI, n. ${ }^{\circ}$ 52, pp. 107-134. DOI: <https://doi.org/10.2307/4531124>.

GUERRERO, Javier y BouZAGLO, Nathalie (comps.) (2009), Excesos del cuerpo. Ficciones de contagio y enfermedad en América Latina. Buenos Aires, Eterna Cadencia.

JITRIK, Noe (1995), Historia e imaginación literaria. Las posibilidades de un género. Buenos Aires, Editorial Biblos.

KIRKPATRICK, Susan (1991), Las románticas. Escritoras y subjetividad en España (1835-1850). Valencia, Universitat de Valencia.

LANDER, María Fernanda (2003). Modelando corazones. Sentimentalismo y urbanidad en la novela hispanoamericana del siglo XIX. Rosario, Beatriz Viterbo.

LITVAK, Lily (1980), Erotismo de fin de siglo. Barcelona, Antonio Bosch.

LUKÁCS, Georg (1972), La forma classica del romanzo storico. Torino, Giulio Einaudi Editore.

MASIELLO, Francine (1997), Entre civilización y barbarie. Mujeres, nación y cultura literaria en la Argentina moderna. Rosario, Beatriz Viterbo.

Mollor, Silvia (2012), Poses de fin de siglo. Desbordes del género en la modernidad. Buenos Aires, Eterna Cadencia Editora.

ORDIZ, Javier (2010), "El naturalismo en Hispanoamérica. Los casos de 'En la sangre' y 'Santa'”. Alicante, Centro Virtual Cervantes. Consultado en <http://www.cervantesvirtual.com/nd/ark:/59851/bmck6513> (21/10/2017).

Peluffo, Gabriel (1996), "Construcción y crisis de la privacidad en la iconografía del Novecientos", Barran, José Pedro, Caetano, Gerardo et al. (dirs.), Historia de la vida privada en Uruguay. El nacimiento de la intimidad. Montevideo, Editorial Santillana. 
RocCA, Pablo (1996), "Mujer y privacidad en la literatura uruguaya (1890-1920)", Barran, José Pedro, Caetano, Gerardo et al. (dirs.), Historia de la vida privada en Uruguay. El nacimiento de la intimidad. Montevideo, Editorial Santillana.

RODRíGueZ MONEGAL, Emir (1968), Vínculo de sangre. Montevideo, Editorial Alfa.

RODRíguEZ Villamil, Silvia (1996), "Vivienda y vestido en la ciudad burguesa (1880-1914), Barran, José Pedro, Caetano, Gerardo et al. (dirs.), Historia de la vida privada en Uruguay. El nacimiento de la intimidad. Montevideo, Editorial Santillana, pp. 75-112.

SARLO, Beatriz (2012), Signos de pasión. Claves de la novela sentimental del Siglo de las Luces a nuestros días. Buenos Aires, Editorial Biblos.

SCHAEFFER, Jean Marie (2006), ¿Qué es un género literario? Madrid, Akal.

Silva BeAuREgARD, Paulete (2012), "Una receta contra la nostalgia. Zarate de Eduardo Blanco", Revista Javeriana, vol. 16, n. ${ }^{\circ}$ 31, pp. 135-161.

SKINNER, Leo (2006), "El discurso religioso y los papeles de las mujeres en el periodismo decimonónico hispanoamericano", Revista lberoamericana, vol. LXXIl, n. ${ }^{\circ}$ 214, pp. 61-76. DOI: <https://doi.org/10.5195/reviberoamer.2006.6l>.

SOMMER, Doris (2004), Ficciones fundacionales. Bogotá, Fondo de Cultura Económica.

UNZUETA, Fernando (2005), "Escenas de lectura. Naciones imaginadas y el romance de la historia en Hispanoamérica", Araucaria. Revista lberoamericana de Filosofia, Política y Humanidades, Año 6, n. ${ }^{\circ}$ 13, pp. 124-165.

WILLIAMS, Raymond (2000), Marxismo y literatura. Barcelona, Ediciones Península.

Zo, Ramiro (2007), "Funciones de la novela sentimental hispanoamericana durante el siglo XIX", CILHA, vol. 8, n. ${ }^{\circ}$ 9. Mendoza: Universidad Nacional de Cuyo, pp. 79-97.

ZuBILlAGA, Carlos y Cayota, Mario (1988), Cristianos y cambio social en el Uruguay de la modernización. Montevideo, Ediciones de la Banda Oriental. 